\title{
Quinze anos de ciclos no ensino fundamental: um balanço das pesquisas sobre a sua implantação*
}

\author{
Candido Alberto Gomes**
}

Universidade Católica de Brasília, Mestrado em Educação e UNESCO

Num país com modestas tradições avaliativas e marcado pela "pedagogia da repetência", que é uma perversão da avaliação, é importante indagar em que medida experiências como os ciclos no ensino fundamental têm sido implantadas, quais os fatores favoráveis e desfavoráveis, os acertos e enganos cometidos. Sem buscar fazer uma história das tentativas de superação da estrutura seriada no Brasil, o que originaria outro trabalho, cabe recordar que a primei-

* Trabalho fundamentado no relatório apresentado no Seminário Internacional sobre Desseriação no Ensino Fundamental, realizado em maio de 2003, sob o patrocínio da Universidade Católica de Brasília, UNESCO, Secretaria de Educação Infantil e Fundamental do Ministério da Educação e Embaixada da França. Com a colaboração de Myriam Christiano Maia Gonçalves e Alda Lino dos Santos Pereira, mestrandas em educação da Universidade Católica de Brasília.

** $\mathrm{O}$ autor agradece os inestimáveis estímulo intelectual e apoio financeiro da UNESCO e da Universidade Católica de Brasília, bem como a atuação do sistema de bibliotecas dessa universidade e da biblioteca da UNESCO. ra geração de inovações no campo da desseriação está relacionada ao ciclo básico de alfabetização, adotado, no início, por São Paulo (1984) e Minas Gerais (1985), no bojo de um movimento renovador decorrente da vitória eleitoral da oposição nesses estados. Várias outras unidades federativas e municípios adotaram os ciclos nos anos seguintes. No que se poderia chamar de segunda geração de inovações, destacam-se a Escola Plural, criada em Belo Horizonte, e a progressão continuada no estado de São Paulo. Esta se fundamentou na última Lei de Diretrizes e Bases (LDB) que, em 1996, abrigou as experiências anteriores e abriu caminho para outras inovações.

Buscando percorrer os cerca de quinze anos de pesquisas publicadas, foi feito um levantamento em bases de dados nacionais, catálogos universitários e bibliotecas eletrônicas, após o qual se procedeu à seleção dos trabalhos que pudessem oferecer contribuições do ponto de vista das políticas educacionais. Foram também utilizadas referências bibliográficas de publicações e, em certos casos, a busca manual. Cabe assinalar que as investigações localizadas são muitas vezes pontuais, dentro das possibilidades de traba- 
lhos acadêmicos, e concentradas nas regiões mais desenvolvidas, que tomaram a dianteira dessas inovações e são também as mais bem documentadas. Predominam os estudos de caso e as análises de dados agregados. No primeiro caso, ganha-se em profundidade e compreensão, porém a generalizabilidade é muito limitada, enquanto a seleção dos casos e todo o processo de pesquisa sofrem o risco de eventuais vieses, o que não é privilégio deste tipo de pesquisa. Poucos são os projetos de avaliação de amplitude, o que sugere que talvez se evitem avaliações externas de certas políticas públicas. Em alguns casos, o autor teve acesso a relatórios de pesquisas promovidas por secretarias de educação que não está autorizado a divulgar. Sistematicamente, os resultados apresentados eram negativos.

É interessante assinalar, numa visão ampla, que os resultados são mistos, ora acusando aprovação, retenção e evasão menores antes que depois da implantação do ciclo básico, enquanto outras pesquisas, analisando períodos mais longos, encontraram benefícios na promoção. No entanto, com a sombra da seriação mantida pelos professores por trás dos ciclos, diversas distorções foram constatadas: a transferência do primeiro pico de reprovação para o fim do ciclo básico e para a quinta série, a definição dos conteúdos curriculares do ciclo básico pelos professores das séries posteriores, e o acréscimo de evadidos entre a segunda e a terceira séries.

Apesar desses resultados, o ciclo básico não foi abandonado, mas teve a sua experiência ampliada, vindo a desembocar, com novas características, na progressão continuada e na expansão e aprofundamento dos ciclos, como é o caso da Escola Plural. Apesar das diferentes administrações públicas e partidos que ascenderam ao poder e de eventuais recuos, estabeleceu-se uma constância curiosa, pela qual pelo menos um relatório, em que pese reconhecer os graves percalços da experiência, recomenda que ela seja alargada ainda mais. Interpretações alternativas são possíveis: de um lado, poderia parecer que a voz da pesquisa tem escasso efeito sobre as políticas educacionais; de outro, os decisores, embora ouvissem a pesquisa, poderiam considerar os defeitos de implantação e evitavam jogar fora o bebê com a água do banho. De qualquer forma, a persistência, governos a fio, com mudança de corpo ou de roupagem, indica que grupos influentes têm manifestado confiança na desseriação, que, afinal, veio a se tornar faculdade legislativa.

Em face da abrangência e riqueza da literatura, o foco deste trabalho incidirá sobre aspectos gerais favoráveis e desfavoráveis à implantação dos ciclos e outras formas de desseriação. Não serão particularizadas experiências, porque seria objeto de outro trabalho.

\section{Aspectos favoráveis aos ciclos}

Juntando as peças de um complicado e parcial mosaico, o Quadro 1 sumaria os principais aspectos favoráveis detectados. De modo geral, as pesquisas apontam medidas de valorização do magistério, que melhoraram suas condições de trabalho em face das tarefas mais complexas da organização em ciclo. Além disso, destacam a sua participação no processo e as suas qualificações. Por fim, no que se refere à gestão, emergiram aspectos como o encadeamento de ações ao longo da burocracia educacional, com a participação do diretor.

Os principais fatores apontados são quase óbvios e indispensáveis à efetivação de quaisquer inovações educacionais com certo nível de complexidade, como os ciclos, o que indica que se acertou em condições simples e elementares (o contrário, como se verá, também é verdadeiro). O magistério precisa compreender e aderir à inovação, ser valorizado, ter mais tempo para se dedicar aos alunos e contar com certa experiência para enfrentar os desafios de uma proposta complexa. Os docentes necessitam também de uma formação continuada eficaz, junto à escola e não em programas de massa, além de jornada ampliada. Aliás, os professores que tinham sucesso com alunos "difíceis", isto é, os mais aptos a lidar com a diversidade, eram mais favoráveis à inovação, precisam ser acompanhados, bem como compreender as 
inovações e apoiá-las. O projeto pedagógico, como depois veio a estabelecer a $L D B$, precisa envolver toda a comunidade escolar. Evidentemente, o diretor e os coordenadores devem apoiar tal projeto e promover clima favorável à aprendizagem na escola. Outros esteios são os alunos e suas famílias. Os alunos, particularmente, precisam ter mais tempo letivo para melhorar a sua aprendizagem, desde que esse tempo não abrigue a repetição do que se faz no tempo usual.

Quadro 1 - Aspectos favoráveis à implantação dos ciclos: evidências de pesquisas selecionadas

Medidas essenciais comuns a quatro unidades federativas (Zapponi, 1991)

- Compreensão bem difundida de nova concepção de ensino-aprendizagem

- Processos eficazes de comunicação com o magistério (também Silva \& Davis, 1994)

- Medidas de valorização do magistério

- Redução do tempo de regência do professor (também Ambrosetti, 1990)

- Aumento da jornada letiva (também Ambrosetti, 1990; Mainardes, 2001; Duran, 2002*)

- Turmas menores, até 30 alunos

- Modificação dos registros escolares para inclusão dos aspectos qualitativos do rendimento e da aprovação global

\section{Outros aspectos ligados ao magistério}

- Participação do magistério (Ambrosetti, 1990; Silva \& Davis, 1994; Guimarães, 2001)

- Tempo de experiência no magistério e na escola (Ambrosetti, 1990)

- Oportunidades de aperfeiçoamento e atualização contínuos (Ambrosetti, 1990; Soares, 2002), bem aproveitadas e descentralizadas (Silva, Davis \& Espósito, 1996)

- Desenvolvimento profissional com impacto sobre suas identidades profissionais (Fernandes \& Franco, 2001)

- Clara compreensão da avaliação da aprendizagem (Fernandes \& Franco, 2001)

- Experiências exitosas com alunos considerados difíceis favorecem apoio à inovação (Fernandes \& Franco, 2001)

- Tempo suficiente para professores estudarem e se reunirem na escola (Guimarães, 2001)

(continua)

* A jornada única acarretou o aumento global de $10 \%$ na aprovação dos alunos em relação às classes de ciclo básico, na Grande São Paulo. (continuação)

- Desenvolvimento de novos valores éticos e políticos (Dalben, 1998)

\section{Aspectos ligados à gestão}

- Maiores investimentos financeiros (ciclos não são forma de barateamento) (Mainardes, 2001)

- Ações coerentes e unificadas no sistema (Mainardes, 2001)

- Projeto pedagógico envolvendo toda a comunidade escolar (Silva, Davis \& Espósito, 1996; Mainardes, 2001)

- Envolvimento e apoio do diretor (Ambrosetti, 1990; Bonel, 1993; Paro, 2000)

- Coordenação atuante (Silva, Davis \& Espósito, 1996; Paro, 2000)

- Clima favorável da escola, com bom relacionamento entre direção e professores, professores entre si e com a comunidade (Ambrosetti, 1990)

- Menor número de alunos por turma (Guimarães, 2001)

- Acompanhamento pedagógico dos alunos e famílias (Guimarães, 2001)

- Jornada docente ampliada (Paro, 2001)

- Contexto favorável de reforma mais ampla (Paro, 2001)

Além disso, os ciclos exigem medidas complexas de implantação, com ações coerentes, como deve ocorrer em todas as burocracias públicas e privadas, mesmo os sistemas escolares tendo desvios significativos em relação às concepções clássicas. Também requerem maiores investimentos financeiros, o que indica não serem formas de, aritmeticamente, baratear a educação. Eles podem levar a grandes economias, porém, ao proporem uma educação de melhor qualidade, sem os vícios da pedagogia da repetência, incorrem em custos, que, naturalmente, podem ser compensados pelos cortes do desperdício. O desenvolvimento de novos valores éticos e políticos é também necessário, visto que as inovações introduzidas representam verdadeira revolução na escola. Se, à primeira vista, o Quadro 1 pode sugerir medidas eminentemente técnicas, deve-se considerar que, sendo a escola um grupo social instituído, a desseriação afeta o contrato social em que ela se baseia (Crahay, 1996, 2000), exigindo nova atuação de cada um dos seus componentes.

Em outras palavras, agir segundo as evidências correntes de pesquisa no panorama internacional foi o que facilitou a adoção e a implantação dos ciclos. Clima da escola, papel do diretor, adesão consciente dos professores, protagonismo dos professores, aumen- 
to da jornada escolar e outros aspectos são bastante conhecidos da literatura (por exemplo, Scheerens \& Bosker, 1997; Scheerens, 2000). Respeitar que as redes escolares são grandes burocracias e precisam estabelecer elos coerentes e firmes em sua ação, com fluxos de baixo para cima e de cima para baixo, foi também outro fator. As pesquisas aparentemente apuraram com rigor esses aspectos favoráveis.

Uma lição que parece óbvia, mas nem sempre é levada em conta na prática, trata da participação dos professores. As melhores concepções pedagógicas e as melhores medidas da gestão frustram-se se os professores não são persuadidos e preparados para levar a efeito determinadas inovações. Sem dúvida, os sistemas escolares são burocracias públicas, mas não típicas burocracias, em que o taylorismo-fayolismo possa florescer com facilidade (aliás, já não floresce sequer nas empresas chamadas produtivas). Sejam consideradas como instituições flexivelmente articuladas ou de outra forma, seu modo de atuação e sua estrutura não encontram no professor um executor automático de tarefas fáceis, porém um sujeito (social), usualmente com elevado grau de "espírito de corpo", que depende do convencimento, da participação e da preparação para tarefas complexas (Vasconcellos, 1999). Não adianta tratar o professor como objeto nem na escola tradicional nem na "renovada". Como a América Latina parece não ter levado em devida conta esses aspectos nas últimas décadas, de certo modo fica-se a constatar o óbvio, como advertência para o presente e para o futuro.

Igualmente, são importantes dois atores, a serem convencidos dos propósitos e das vantagens das inovações: os alunos e as suas famílias. Os primeiros convivem na escola num ambiente em que se mesclam consenso e conflito. Mudanças de normas e alterações no regime de incentivos e sanções são fundamentais para a sua conduta. Quanto aos pais, junto com os alunos, sobretudo a partir de certa idade, eles têm aspirações sociais importantes em face da escolaridade e decidem sair ou permanecer nela, arcando com os seus custos, mesmo os de oportunidade (isto é, de cursar a escola em vez de fazer outra coisa).

\section{Aspectos desfavoráveis aos ciclos}

Com freqüência são essas lições negligenciadas que emergem dos aspectos desfavoráveis, muito mais numerosos, identificados pelas pesquisas, alguns com grande reiteração, mesmo ao longo do período pesquisado (Quadro 2). Começando pela gestão educacional, encontra-se a freqüente posição reformista de cima para baixo. Além disso, divisões internas e descontinuidades das burocracias educacionais mostraram-se prejudiciais à implantação de inovações tão delicadas. Na ponta dos sistemas, isto é, na escola, com freqüência foi constatada a falta de um projeto que congregasse os diferentes membros da comunidade educativa em torno dos ciclos, de modo que eles se tornassem caminho efetivo na luta contra o fracasso escolar. Muitas vezes esses atores se apresentavam divididos, desinformados ou não sensibilizados adequadamente. Nas múltiplas situações em que os ciclos apresentavam dificuldades de implantação, o magistério, sem adequados capacitação e envolvimento, não logrou superar os padrões que balizavam sua formação, experiência e rotinas simplificadas (sobretudo na avaliação), rejeitando um caminho mais difícil, porém de resultados tidos como mais promissores. Com isso, no que tange ao currículo e à avaliação houve uma série de desvios, com adesão formal às novas normas, de tal modo que em muitos casos não se verificou a implantação integral dos ciclos. É interessante observar os anos das pesquisas: com muita freqüência se mantêm ao longo do período observado, tanto os acertos quanto os enganos de implantação, com relativa constância temporal tanto dos fatores favoráveis quanto desfavoráveis.

Quadro 2 - Aspectos desfavoráveis à implantação dos ciclos: evidências de pesquisas selecionadas

Aspectos relativos à gestão educacional

- Fragilidade de processos de implantação (Michelotto, 1988; Ambrosetti, 1990; Marques, 1991; Andrade,

(continua) 
1992; Bonel, 1993; Negri, 1994; Mainardes, 1995; Nébias, 1990)

- Falta de discussão e assimilação da proposta (Bonel, 1993; Freitas, 2002; Alavarse, 2002)

- Participação frustrante dos professores, pois não ficou claro que suas opiniões foram levadas em consideração (Ambrosetti, 1990)

- Imposição por decreto, apesar do discurso inicial (Ambrosetti, 1990; Negri, 1994)

- Descontinuidade administrativa (Ambrosetti, 1990; Silva \& Davis, 1994; Negri, 1994; Mainardes, 1995)

- Divergência entre grupos na cúpula da Secretaria Estadual de Educação (Ambrosetti, 1990)

- Insegurança das equipes da Secretaria Estadual de Educação quanto a problemas concretos, aliada à desconfiança das escolas em face da administração central. Concepções negativas mútuas do centro e das escolas. Adaptação rápida das escolas e Delegacias Regionais de Ensino a novos discursos, com aparência de mudança (Ambrosetti, 1990; Nébias, 1990; Bonel, 1993)

- Indefinição quanto a currículo e avaliação por longo tempo; eliminação da seriação sem alterações curriculares (Ambrosetti, 1990; Fernandes \& Franco, 2001)

- Falta de acompanhamento, até mesmo com deficiências dos órgãos regionais (Michelotto, 1988; Ambrosetti, 1990; Marques, 1991; Mainardes, 1995; Rodriguez, 2002)

- Ausência, no sistema de ensino, de medidas para minimizar a resistência à aprovação (Paro, 2001)

- Dificuldade de propor projeto com características universalizantes em meio à heterogeneidade de posições e disponibilidade de práticas docentes (Garcia, 2001)

- Modificações da estrutura escolar (Alavarse, 2002), incluindo reorganização de espaço e tempo (Cangussu, 2001)

- Queda sistemática da participação da Secretaria de Educação do Estado de São Paulo no orçamento total (Duran, 2002)

\section{Aspectos relativos à gestão escolar}

- Falta de projeto pedagógico próprio, envolvendo toda a comunidade escolar, e de comunicação da proposta aos pais (Silva, Davis \& Espósito, 1996; Paro, 2000; Fernandes \& Franco, 2001; Guimarães, 2001; Freitas, 2002)

- Implantação brusca (Garcia, 2001)

- Formação de opiniões desfavoráveis dos pais pelos professores (Paro, 2001). Não envolvimento dos pais/comunicação de noções equivocadas. Temor de que filhos não dominem conhecimentos mínimos (Dalben, 1998; Souza, 2000)

- Representação dos pais sobre a escolaridade, envolvendo a preparação para o trabalho, disciplina e motivação extrínseca (Paro, 2001)

- Falta de comunicação/compreensão dos alunos. Falta de cultivo da auto-avaliação dos alunos (Guimarães, 2001; Paro, 2001)
- Predominância da reprovação e do "credencialismo" como estruturantes da educação escolar (Paro, 2001)

- Opiniões divididas quanto ao remanejamento de turmas, que, praticado indiscriminadamente, tendeu a estratificar os alunos por status socioeconômico (Ambrosetti, 1990; Silva, Davis \& Espósito, 1996)

- Falta de recursos físicos e didático-pedagógicos (Michelotto, 1988; Andrade, 1992; Vianna, Squárcio \& Vilhena, 1992; Negri, 1994). Atribuição contínua de culpa aos "responsáveis", isto é, governantes (Frehse, 2001)

\section{Medidas relativas ao magistério}

- Falta de orientações concretas e educação continuada para o corpo docente (Andrade, 1992; Michelotto, 1988; Ambrosetti, 1990)

- Rotatividade, absenteísmo e greves dos professores (Marques, 1991; Mainardes, 1995; Frehse, 2001)

- Resistência às mudanças curriculares e metodológicas (Ambrosetti, 1990; Guimarães, 2001). Não cabe ao sistema optar por concepções pedagógicas, deixando os professores sem a "muleta" dos procedimentos usuais (Bonel, 1993)

- Não compreensão da proposta (Andrade, 1992), mantendo a concepção de série intacta e a promoção automática levando à acomodação na primeira série e sobrecarga na segunda (Ambrosetti, 1990) ou engarrafamento ao fim dos ciclos (Paro, 2001)

- Reinterpretação dos ciclos como pura promoção automática, levando o aluno a prosseguir, ampliando a defasagem do aprendizado (Frehse, 2001; Guimarães, 2001; Silva \& Melo 2001; Rodriguez, 2002)

- Organização da escola com base em disciplinamento de conteúdos e condutas. Temor de perda de identidade e de carga horária pelos professores (Dalben, 1998)

- Distância entre a formação inicial dos professores e a identidade docente que se constrói (ou se quer construir) nas escolas e movimentos sociais (Soares, 2002)

- Desinteresse do sistema pela identidade profissional do professor, gerando resistências (Silva, Davis \& Espósito, 1996)

- Falta de concepção progressista de educação e condicionamento por visão punitiva de avaliação (Paro, 2000)

- Desconsideração do valor de referência histórica das representações dos professores e da relação entre elas e o papel por eles atribuídos no ensinoaprendizagem (Sousa, 1999)

- Redução da alçada decisória do professor no julgamento do aluno, na progressão continuada (Alavarse, 2002; Freitas, 2002)

- Baixo autoconceito dos professores (Paro, 2000)

- Reprodução pelos educadores adultos da socialização escolar autoritária do seu passado (Paro, 2001) 
(continuação)

\section{Aspectos relativos ao currículo e avaliação}

- Ajustamento formal às novas normas (Guimarães, 2001; Silva \& Melo, 2001)

- Trabalho docente comum para toda a classe, sem atividades diferenciadas (persistência do modelo frontal (Silva \& Davis, 1994)

- Atuação pedagógica colada aos livros didáticos (Silva \& Davis, 1994)

- Planejamento sem apoio nos resultados da avaliação (Silva \& Davis, 1994)

- Acúmulo de conteúdos curriculares (Silva \& Davis, 1994)

- Uso da avaliação bimestral como base, em vez da ficha descritiva, baseada na observação contínua (Silva \& Davis, 1994)

- Parcela de alunos que se saíam bem era o grupo de referência para avaliação - continuação da pedagogia da repetência (Silva \& Davis, 1994)

- Reforço e recuperação precários, em desacordo com as normas do sistema de ensino (Frehse, 2001; Guimarães, 2001)

- Desinteresse do aluno pela avaliação formativa quanto maior a sua idade. Certeza da promoção automática (Frehse, 2001)

- Explicação do fracasso escolar baseada em fatores extra-escolares e na vontade e capacidade do aluno e não intra-escolares (CENPEC, 2001; Paro, 2001; Silva \& Melo 2001)

\section{Aspecto contextual}

- Internalização de relações de dominação, competição e credencialismo, em vez da busca do saber e da concepção de educação como atualização histórico-cultural que suponha didática em que o educando seja autor e construtor da sua aprendizagem (Paro, 2001)

O panorama descerrado é, pois, de freqüente incipiência das alterações, uma vez que os sistemas escolares demonstraram não respeitar algumas características fundamentais de qualquer inovação em grandes burocracias públicas. Assim, a fragilidade dos processos de implantação implicava uma série de acidentes no trajeto do centro até às salas de aula, com elos desentrosados, sem manter a coerência indispensável para que ocorresse algo efetivo nos sistemas escolares. Com uma ação dispersiva e desentrosada, carente de orientação nas diversas etapas, acabava-se por perder o ímpeto renovador e levar a acontecer um espectro daquilo que havia sido previsto. No período de redemocratização nacional, tinha- se claramente em vista que inovações não poderiam fluir no velho esquema do centro planejador - periferia executora. Tanto assim que os projetos, especialmente de São Paulo e Minas Gerais, foram amplamente discutidos com o magistério e numerosas como inéditas - foram as oportunidades de discutir e até de votar proposições. Apesar disso, houve contradições no processo e uma adesão parcial e superficial de parte ponderável do professorado, que não estava convencido de que as propostas superavam a malfadada, mas seguramente conhecida e praticada "pedagogia da repetência". Foi assim que, particularmente no estado de São Paulo, a pesquisa verificou que os professores, chamados a participar no início dos anos de 1980, ofereceram respostas frustrantes para a cúpula renovadora da secretaria da educação, que não poderia aceitar a continuação do status quo. Em conseqüência, o magistério não reconheceu suas opiniões quando a proposta dos ciclos chegou às escolas. Em contrapartida, a década de 1980 foi marcada por longas e freqüentes greves dos professores, que buscavam recompor a sua remuneração, até mesmo por causa do acelerado processo inflacionário.

Em tal clima, eram difíceis o entendimento e a colaboração. No âmbito das mútuas relações de desconfiança, entre escolas e administrações regionais e central, existiam mecanismos de acomodação em que as primeiras se caracterizavam por preservar parte das rotinas, até salutarmente, enquanto as últimas mudavam freqüentemente ao sabor das injunções políticas. Com isso, numerosas unidades escolares se adaptavam epidermicamente aos novos discursos. No caso dos ciclos, o porte da inovação era demasiado grande para manter as aparências de mudança, mas, ainda assim, a resseriação foi constatada por várias pesquisas. Desse modo, embora houvesse a continuidade dos ciclos, sob vários ângulos, dependendo da administração, criou-se uma contradição entre a roupagem democrática da discussão e a resistência do professorado. Também contrastavam o ímpeto renovador e as descontinuidades da gestão central com a ausência ou escassez de um esforço contínuo e persistente da formação continuada do professor, 
que, segundo Alves (2002), só frutificava efetivamente após anos de pacientes esforços. Além disso, as modificações estruturais da escola, mesmo com a reorganização do espaço e tempo, eram de tal porte que não encontravam correspondência no apoio e no trabalho de adesão que deveria ser voltado para os atores envolvidos.

A gestão escolar, por seu lado, ressentia-se da falta de um projeto pedagógico que reunisse as forças da comunidade educativa. A penúria de meios era também significativa. O remanejamento indiscriminado de turmas, numa sociedade desigual, acabou, pelo menos em certos casos, por estratificar os alunos por status socioeconômico, ocasionando oportunidades desiguais que amplificavam as disparidades sociais. No âmbito da escola, portanto, as pesquisas constataram ações insuficientes no sentido de persuadir e cativar os atores principais, dentre eles professores, alunos e suas famílias. Nada mais desaconselhável quando se trata de efetuar uma verdadeira revolução nas finalidades, objetivos, métodos e avaliação na escola.

Do lado do magistério, os problemas típicos da crise fiscal dificultaram adotar uma inovação que toca o nervo da vida e da identidade profissionais do professor. Como não se pode fazer omelete sem quebrar os ovos, não se poderia combater a pedagogia da repetência por meio de meros retoques. Com isso, o professor passou por várias tensões e exerceu a resistência no seio de burocracias que contam com arenas conflituosas, em vez de constituir harmônicos relógios. Uma das mais difíceis veio a ser a alteração do sistema de controles na sala de aula, sem o poder da sanção maior da reprovação, sanção essa que está relacionada com capacidades cognitivas, mas também com comportamentos e atitudes dos alunos, sujeitos a julgamentos e avaliações por caminhos não raro preconceituosos. Como a escola é concebida por alguns autores (por exemplo, Waller, 1967) como um grupo em conflito potencial ou real, em que a frequiência dos alunos e professores e as prescrições curriculares são obrigatórias, à semelhança de uma panela de pressão, nessas circunstâncias o papel das sanções (e não só dos incentivos) pode ser axial (Freitas, 2002).

Assim, não é difícil compreender esse motivo da oposição dos professores aos ciclos, eles que se encontram na ponta do sistema (cf. os resultados de Freitas, 2000; Guimarães, 2001; Frehse, 2001; Paro, 2001; Silva \& Melo, 2001; Rodriguez, 2002). Quanto mais a escolaridade se desenrola num clima de conflito latente ou aberto, mais depende de um sistema de sanções para manter a ordem social. Quanto maior o consenso em que se baseia, ainda que se estabeleçam conflitos, cabem mais os incentivos que as sanções, embora seja difícil manter um grupo social deste tipo sem as últimas (Gomes, 1994). Ora, com a pedagogia da repetência, a coesão da escola depende mais dos conflitos e das sanções que do consenso e dos incentivos. Como resultado, estabelecida a promoção entendida como automática ou de alguma forma facilitada, essa ordem social fica privada de um dos seus maiores ou de seu maior pilar, tendo em vista o corte tradicional da escola. Em conseqüência, os professores tendem a se opor às inovações e, instados por decreto a mudar práticas arraigadas, conseguem não raro cumprir formalmente a legislação e as normas sem modificar a avaliação e suas representações, empurrando a reprovação para o fim do ciclo básico ou, ainda, abandonando o aluno com baixo aproveitamento e desresponsabilizando-se por ele. Isso ocorreu, segundo Sousa (1999), porque a proposta não considerou o valor de referência histórica dessas representações e a relação com o seu papel. Paro (2000, 2001), por sua vez, em pesquisa naturalística, observou a importância de uma tradição punitiva da avaliação na história de vida escolar de professores e da população em geral; o baixo autoconceito do professor, que se compensa com a inculpação do aluno, e a falta de concepção progressista de educação que suponha uma didática em que o educando seja autor e construtor da sua aprendizagem. O professor não tem o foco na aprendizagem do aluno, nem considera os seus resultados como elemento para rever o ensino. Ao contrário, é mais dramático passar sem aprender do que não ter aprendido. 
Ainda no campo do magistério, a situação dos que o compõem leva a refletir cuidadosamente sobre as possibilidades de mudanças radicais e as suas implicações em termos de esforços. Considerando o Ceará, onde também foi adotado o sistema de ciclos, as pesquisas descrevem particularmente as difíceis condições das professoras alfabetizadoras. Uma pesquisa com histórias de vida revelou uma identidade fragmentada, não fundada na crítica e na reflexão, e um discurso baseado no amor e doação pelo magistério. Sem acesso a bens culturais fundamentais na ampliação dos seus conhecimentos, as professoras estavam ausentes de discussões e decisões sobre a sua prática. Com uma formação precária e inadequada, não encontravam esteio na competência, achando que qualquer pessoa podia ser professora, principalmente alfabetizadora (Lima, 1995). Outra pesquisa qualitativa revelou o entendimento, pelo menos por uma parte delas, com a sua modesta formação, de que, com a promoção automática, não precisavam mais ensinar. A formação continuada, que poderia oferecer condições de superação, tinha aspectos positivos, porém era rala e frágil, consistindo de cursos pouco freqüentes (uma semana, uma ou duas vezes ao ano, quando eram oferecidos), com falta de periodicidade, às vezes interrompidos, e caracterizados geralmente pela dissociação em face das demandas docentes e pelo grande peso da teoria (Mamede, 2000). Este mosaico das condições docentes do meio urbano e rural num estado da Região Nordeste indica o quanto há por fazer e o quanto o que é feito deixa a desejar, apontando, mais uma vez, para a precariedade da implantação.

A dificuldade, portanto, reside no fato de que as mudanças da escola se realizam epidermicamente, coexistindo processos incongruentes. Conforme as pesquisas resenhadas, o tratamento dispensado pelos sistemas aos professores, muitos deles praticantes e adeptos da pedagogia da repetência, não chegou a ser equacionado do modo mais feliz, com a formação continuada e o acompanhamento requeridos. Ao contrário, parece que se convocaram os soldados para uma guerra sem que eles estivessem preparados e convencidos da legitimidade desta. Pior ainda, tocouse fundo no papel e na visão desses atores sem prever como atuar em face das conseqüências, o que se assemelha à conduta do aprendiz de feiticeiro.

Com isso, à semelhança de outras inovações educacionais, as novas práticas com freqüência foram reinterpretadas com a manutenção das antigas, mantendo o corpo velho sob vestes novas. É o que dizem as constatações sobre currículo e avaliação. Mais ainda, sistemas de ensino ou redes inteiras, cheios de boas intenções, tenderam a fazer opções metodológicas gerais para a alfabetização. Com isso, muitos professores passaram a ter a angústia de abandonar os anatematizados modelos antigos sem dominar os novos, quando é discutível, observada a autonomia da escola, que se estabeleçam opções uniformes para todas elas.

No caso dos ciclos, a parte mais visível foi a promoção interpretada como automática, precisamente o maior pomo de discórdia, abrindo possibilidades de ou se reduzirem os ciclos à ponta do iceberg ou manter as práticas tradicionais sob as referidas vestes novas, numa evidência de que Almeida Júnior (2002) não foi escutado nem hoje nem nos anos de 1950, quando lutava contra o fracasso escolar, mas alertava para o risco da promoção automática incondicional. Fica claro das evidências de pesquisa (cf. também Barros \& Mendonça, 1998; Espósito, Davis \& Nunes, 2000) que a reprovação não leva a aprender mais, antes, pelo contrário, aumenta a probabilidade de nova reprovação, enquanto mais de uma reprovação tende a elevar a probabilidade de repetência. Além disso, autores como Pedro Demo (1998) alertam para a tentação de promover o discente sem a devida aprendizagem, com o argumento de não causar danos à autoestima do aluno, quando é preferível a pedagogia da verdade. A promoção sem aprendizagem correspondente constitui um ônus sobretudo para a escola pública e para os alunos socialmente menos privilegiados, pois desmoraliza a escola pública e torna-a coisa pobre para o pobre.

Desse modo, se faltam evidências que justifiquem e legitimem a reprovação - e reprovação em massa - 
que ainda é praticada no Brasil, a leniência (que nada tem a ver intrinsecamente com os ciclos, mas estes correm o risco de ser a ela reduzidos) não é melhor remédio. Ao contrário, pode-se esconder uma aprendizagem medíocre sob o manto da regularização de fluxo, como têm evidenciado os resultados do Sistema de Avaliação da Educação Básica (SAEB) e do Programme of International Student Assessment (PISA). As exigências podem ser niveladas por baixo, como por meio de um rolo compressor, deixando-se de lado a necessidade de exigências crescentes de aprendizagem. Com isso, embora não querendo, pode-se gerar o pior dos mundos: regulariza-se o fluxo de alunos e se reduzem os custos, satisfazendo a gestores e às eternas limitações orçamentárias da educação; pais e alunos incautos ficam satisfeitos porque, não havendo reprovação, há ilusão de aprendizagem; o trabalho do professor é, sob vários aspectos, facilitado, na medida em que se requer pouco dos alunos e, por extensão, do corpo docente; o sistema educacional, enquanto olha para o seu umbigo, fica satisfeito com a adequação do país a alguns indicadores estatísticos internacionais. Em outras palavras, fica tudo pior que dantes no quartel de Abrantes. Portanto, corre-se o risco de avançar na quantidade e contornar os problemas da qualidade e da democratização. Como os alunos pouco aprendem, a começar pelos mais pobres, mantêm-se estruturas injustas.

Outra implicação importante dos descaminhos entre o centro do sistema e a escola e vice-versa é o dilema (Frigerio, 2002): as reformas reformam as escolas ou as escolas reformam as reformas? Discursos reformistas, não raro incongruentes com a ação, defrontam-se com as culturas institucionais escolares, com a gramática da escola. Esta compreende um sistema de regras explícitas e implícitas de uma instituição, utilizadas de maneira consciente ou não, e que, como a gramática da língua, não precisa ser entendida conscientemente para funcionar. Se as mudanças institucionais e as reformas não conseguem transformar algo da gramática da escola, estão fadadas a não se institucionalizar. Daí a necessidade de mudar as representações, os valores, as crenças, as normas e as regras do jogo institucional. É isso o que dá sentido à escola como instituição social e, portanto, é o que precisa ser considerado pelas reformas. Todavia, como evidencia um estudo de caso, as reformas tendem a ser realizadas no bojo de uma relação de poder historicamente constituída pelos atores sociais que fazem as secretarias de educação e as escolas. Quando uma secretaria provoca mudanças, implantando inovações, não propõe que os atores que atuam no espaço escolar reflitam sobre a sua prática e inovem. Ao contrário, espera que, sem reflexão, a escola coloque em prática suas diretrizes, pois desacredita o saber da escola. No entanto, há espaço para resistência, porque, ao mesmo tempo que reproduz o discurso oficial, a escola produz outros discursos, que atendem às necessidades do cotidiano pedagógico. Com isso, em vez de se construir uma relação de parceria, mantém-se uma limitada relação de poder, que se repete a cada governo, com suas mudanças, que, por sua vez, requerem pré-requisitos de fundamentação teórico-prática geralmente não atendidos (Braid, 2001).

Por isso, a simples descentralização da gestão é insuficiente, precisando atuar sobre o âmago da escola e, a partir do centro, desenvolver dinâmicas de apoio e estímulos externos. Trata-se, portanto, de território delicado, onde interagem forças múltiplas e onde a abordagem apenas técnica tem comprovado não alcançar êxito.

\section{Conclusões}

Antes de mais nada, cabe reiterar que, no período focalizado, a educação pública, viveu - e continua a viver - a crise fiscal e a crise de identidade do Estado, com as suas mudanças de rota e suas ambigüidades nos últimos vinte anos, incluindo problemas crônicos de natureza organizacional, subfinanciamento, má alocação de recursos e outros, além das notórias e subreptícias resistências à mudança. Evidências de pesquisas aqui resenhadas revelam que projetos meritórios de desseriação e combate ao fracasso escolar tenderam a sofrer substanciais desgastes e distorções na trajetória entre os centros planejadores e a execu- 
ção nas escolas, mostrando com freqüência outra face nas salas de aula, pelo menos em casos pesquisados. Num ambiente histórico de crise do Estado e escassez de recursos, foram realizadas transformações profundas que não encontravam correspondência nem nas depauperadas burocracias públicas, nem nas verbas adequadas para colocar as escolas em condições de atuar de maneira inovadora. Certamente, parte ponderável dessas contradições não acontece por acaso, conforme o texto inesquecível de Anísio Teixeira (1983) sobre as contradições entre os valores proclamados e os valores reais na educação brasileira. Temos longa tradição de propostas brilhantes encarna-

Quadro 3 - A tortuosa trajetória das propostas à sala de aula

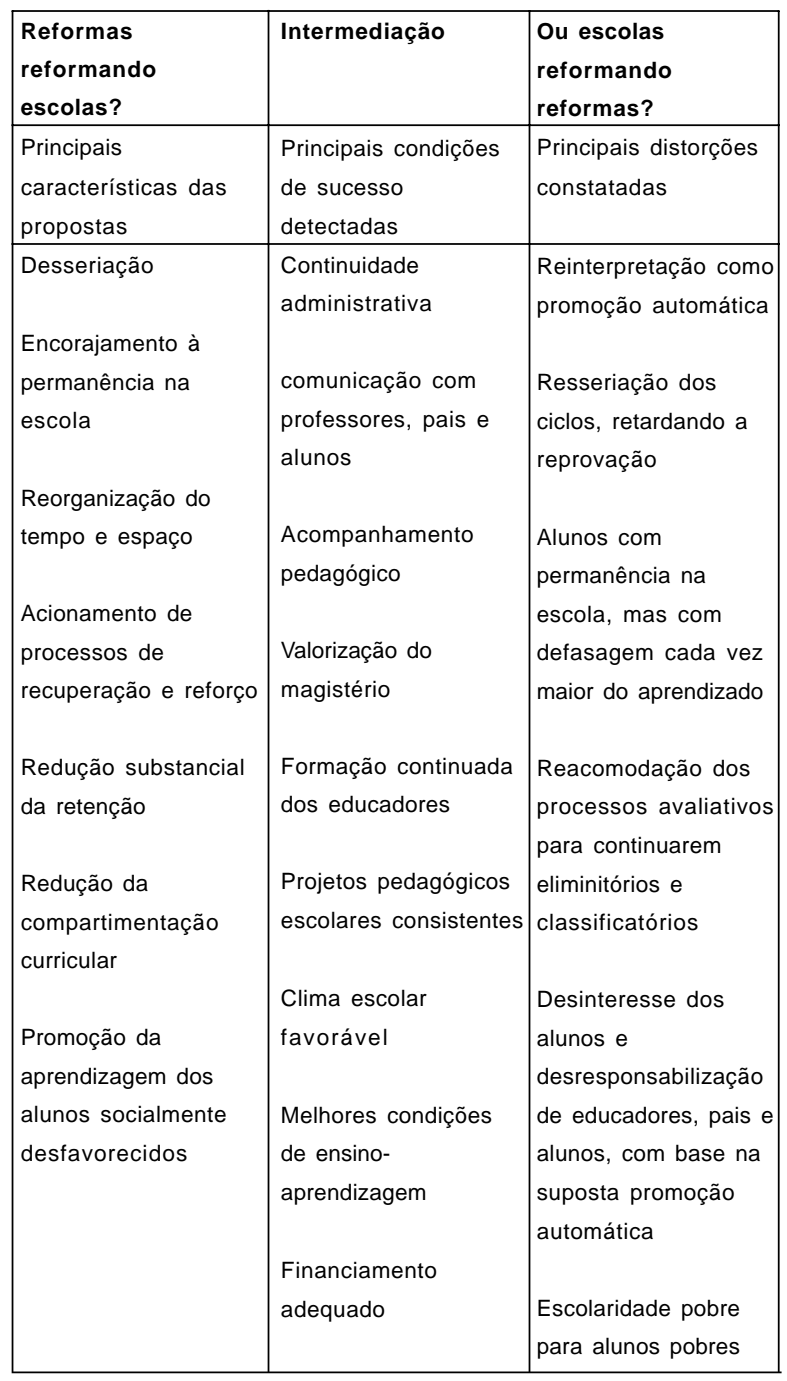

rem na realidade de maneira empobrecedora, gerando não raro efeitos contrários aos pretendidos. O Quadro 3 , como numa fotografia seletiva, procura captar os claros mais brilhantes e os escuros mais intensos dos contrastes entre projetos e realidade. Não se trata, de modo algum, de afirmar que as propostas destes dois decênios foram malsucedidas ou que nada foi feito el ou que predominantemente se perverteu. Esta seria uma visão pessimista e injusta para tão ingentes esforços que redundaram, pelo menos, no aumento substancial do acesso e na progressiva correção do fluxo. Trata-se de alertar contra os inequívocos desvios e distorções. O quadro referido se fixa no pretendido e no não realizado ou distorcido em situações selecionadas. No meio, incluem-se as principais condições de sucesso reveladas pelas próprias pesquisas.

Retornando a um clássico, a visão do Quadro 3 é a da contemporaneidade do que não é coetâneo. A escola velha e a escola nova coexistem em diversas proporções, com diversos matizes e contradições, como intenção e realidade. A mescla desses elementos conduz, em muitas situações, o velho a não ser tão velho e a ficar pior que o novo. É o caso do desmoronamento da escola tradicional pela introdução do que é percebido como promoção automática, em que os atores escolares podem ser lançados ao pior dos mundos, quando o velho ruiu e o novo ainda não foi edificado ou foi implantado de maneira distorcida. Pode-se afirmar que isso é inerente às mudanças profundas, mas é preciso estar atento a esses riscos e problemas, que devem ser corretamente enfrentados. Roma não se fez num dia, mas já se passaram duas décadas. A implantação correta das políticas depende, entre outros fatores, mas certamente com destaque, do envolvimento prévio e continuado dos professores (Fernandes \& Franco, 2001) e demais atores, num processo longo e perseverante. Do topo das secretarias de educação às bases da sala de aula existem níveis decisórios variados. E esta é uma diferença da escola em face de outras organizações: todos os níveis têm uma alçada decisória significativa. $\mathrm{O}$ entrosamento coerente entre esses níveis é uma das condições indispensáveis ao funcionamento e ao êxi- 
to das inovações. Ou seja, é necessário que haja a orquestração adequada, em que os diversos sujeitos envolvidos exerçam os seus papéis sem serem objetificados ou atropelados. Ademais, como as medidas mais dolorosas, caras e complexas podem ser adiadas, contornadas ou mal tomadas, o risco é o de se agir como aprendiz de feiticeiro. A não retenção dos alunos não é só uma questão técnica, ao contrário, é um dos eixos do contrato social em que se assenta a escola (Crahay, 1996). Se o contrato tradicional e opressor é rompido, ótimo; mas, se não houver contrato novo no lugar ou se o novo for tão difuso que não comprometa as partes, pode-se piorar, em vez de melhorar. Não significa que isso forçosamente aconteça, porém que pode acontecer. Esta parece uma questão do maior impacto, além do financiamento e alocação adequada de recursos, para que não se tenha simplesmente uma sopa mais aguada, servida a um número maior de comensais, ou, ainda, vinho velho em odres novos. O rico conceito de contrato social apresentado por Crahay nos remete ao do pacto educativo, defendido pela Organização das Nações Unidas para a Educação, Ciência e Cultura (UNESCO) como caminho por excelência para realizar mudanças duradouras em educação (Tedesco, 1998; Gomes, 2002), substituindo a desgastante verticalidade pela concertação de atores em torno de valores comuns, incentivos e condutas consensuadas.

Por fim, cabem algumas observações a respeito da pesquisa educacional realizada nesses quinze anos. $O$ balanço revela uma centena de qualificados trabalhos de conclusão de mestrado e doutorado de que todos podem orgulhar-se. Geralmente financiados pelos próprios autores, seu alcance é em quase todos os casos pontual e têm caráter qualitativo, conduzindo à generalização naturalística. Em certos casos, sem que pareçam prejudicar-se significativamente suas conclusões, transparece ou a admiração por experiências consideradas bem-sucedidas ou o desejo de recortar segmentos da realidade em que certas políticas se mostram pouco viáveis ou malsucedidas, apontando para justas necessidades de reformulações. Poucas são as pesquisas de grande porte que avaliam a fun- do, com desenhos apropriados, as experiências implantadas em sistemas de ensino inteiros. É o panorama da falta de política de pesquisa educacional e da falta de avaliação das políticas educacionais. Trata-se de uma situação de heroísmo, em que os pósgraduandos custeiam a grande maioria das pesquisas disponíveis, porém, ao mesmo tempo, um caso de inadequação, por faltar pesquisa institucional à altura das mudanças que as políticas buscam introduzir. Esta é, portanto, mais uma questão a ser contemplada, para que, a cada quadriênio, ou períodos menores, as políticas educacionais não atirem no escuro.

Do ponto de vista metodológico, falta aprofundamento da pesquisa quantitativa, por meio da aplicação de variados modelos aos dados agregados existentes, como os do SAEB e a outros especialmente coletados. Afinal, há muito não cabe considerá-la como necessariamente conservadora. A sociologia da educação levou grandes sacudidelas de pesquisas quantitativas de grande porte, não só dos próprios relatórios, mas também dos que souberam reutilizar os seus dados. Além disso, as pesquisas de caráter qualitativo muito teriam a oferecer se avaliassem situações escolares bem-sucedidas na desseriação. A "literatura do sucesso" precisa ser comparada à "literatura do fracasso", que, por motivos compreensíveis, apresenta grande difusão. Por fim, formando o terceiro lado do triângulo, a interação entre pesquisas quantitativas e qualitativas poderia levar ao enriquecimento mútuo, permitindo explorar a realidade a partir de diversos ângulos e níveis de generalizabilidade. Afinal, embora sejamos como peixes dentro de lagos, o distanciamento crítico não faz mal a ninguém. Não cabe retornar aos fatos sociais como coisas, mas é preciso identificar cuidadosamente as nossas inclinações quanto às situações analisadas.

\section{CANDIDO ALBERTO GOMES, mestre em sociologia pelo} Instituto Universitário de Pesquisas do Estado do Rio de Janeiro (IUPERJ) e doutor em educação pela Universidade da Califórnia (Los Angeles), atua na área de políticas educacionais. Livros mais recentes: Traduzindo em ações o Plano Nacional de Educação 
(organizador, Brasília: UNESCO e Senado Federal, 2002); Dos valores proclamados aos valores vividos: traduzindo os atos $\mathrm{e}$ princípios das Nações Unidas e da UNESCO para projetos escolares e políticas educacionais (Brasília: UNESCO, 2001, edições em português e inglês); $O$ ensino médio no Brasil ou a história do patinho feio recontada (Brasília: Universa e UNESCO, 2000). E-mail: clgomes@terra.com.br

\section{Referências bibliográficas}

ALAVARSE, Ocimar Munhoz, (2002). Ciclos : a escola em (como) questão. Dissertação de mestrado. Faculdade de Educação da Universidade de São Paulo.

ALMEIDA JÚNIOR, Antonio Ferreira, (2002). Repetência ou promoção automática. In: CONSELHO ESTADUAL DE EDUCAÇÃO. A voz dos educadores: textos escolhidos. São Paulo, CEE, p. 72-81.

ALVES, Maria Leila, (2002). A formação continuada no ciclo básico: memórias. XI ENDIPE: Encontro Nacional de Didática e Prática de Ensino. Goiânia, maio. Manaus: Sonopress Rimo da Amazônia. CD-ROM.

AMBROSETTI, Neusa B, (1990). Ciclo básico: uma proposta vista pelas professoras. Cadernos de Pesquisa, no 75, p. 57-70.

ANDRADE, Irene Rodrigues, (1992). Ciclo básico: da proposta transformadora de alfabetização à realidade de sua prática. Dissertação de mestrado. Faculdade de Educação da Universidade Estadual de Campinas.

BARROS, Ricardo Paes de, MENDONÇA, Rosane, (1998). Conseqüências da repetência sobre o desempenho educacional. Brasília: IPEA.

BONEL, Mônica Maia, (1993). O ciclo básico: estudo de caso de uma política pública no Estado de São Paulo. Dissertação de mestrado. Faculdade de Educação da Universidade Estadual de Campinas.

BRAID, Liana Maria Carvalho, (2001). (Des)caminhos das mudanças na sistemática de avaliação em escolas públicas municipais. Dissertação de mestrado. Faculdade de Educação da Universidade Federal do Ceará.

CANGUSSU, Maria Aparecida Rodrigues, (2001). Progressão continuada na escola pública mineira: limites e avanços. Dissertação de mestrado. Faculdade de Educação da Pontifícia Universidade Católica de Campinas.

CENTRO DE ESTUDOS E PESQUISAS EM EDUCAÇÃO, CUL-
TURA E AÇÃO COMUNITÁRIA (CENPEC), (2001). Aceleração de estudos: enfrentando a evasão no ensino noturno. São Paulo: Summus.

CRAHAY, Marcel, (1996). Podemos lutar contra o insucesso escolar? Lisboa: Instituto Piaget.

, (2000). Poderá a escola ser justa e eficaz? Da igualdade das oportunidades à igualdade dos conhecimentos. Lisboa: Instituto Piaget.

DALBEN, Ângela Imaculada Loureiro de Freitas, (1998). A avaliação escolar: um processo de reflexão da prática docente e da formação do professor no trabalho. Tese de doutorado. Faculdade de Educação da Universidade Federal de Minas Gerais.

DURAN, Marília Claret Geraes, (2002). A organização do ciclo básico e a concepção de alfabetização-memórias. XI ENDIPE: Encontro Nacional de Didática e Prática de Ensino. Goiânia, maio. Manaus: Sonopress - Rimo da Amazônia. CD-ROM.

DEMO, Pedro, (1998). Promoção automática e capitulação da escola. Ensaio: Avaliação de Políticas Públicas em Educação, v. 6, no 19, p. 159-190.

ESPÓSITO, Yara Lúcia, DAVIS, Claudia, NUNES, Marina Muniz Rossa, (2000). Avaliação de sistemas de ensino: do levantamento de índices à descrição de habilidades - um estudo da $5^{\mathrm{a}}$ série. Em Aberto, v. 17, n 71, jan., p. 100-128.

FERNANDES, Claudia, FRANCO, Creso, (2001). Séries ou ciclos: o que acontece quando os professores escolhem? In: FRANCO, Creso (org.). Avaliação, ciclos e promoção na educação. Porto Alegre: Artmed, p. 55-68.

FREHSE, Eike, (2001). Democratização em xeque? Vicissitudes da progressão continuada no ensino paulista em 1999. Dissertação de mestrado. Faculdade de Educação da Universidade de São Paulo.

FREITAS, Elias José Lopes de, (2000). A implementação da política pública Escola Plural: as representações sociais dos pais sobre seus princípios de avaliação. Belo Horizonte, 2000. Dissertação de mestrado. Faculdade de Educação da Universidade Federal de Minas Gerais.

FREITAS, Luiz Carlos de, (2002). Ciclos de progressão continuada: vermelho para as políticas públicas. Eccos Revista Científica, São Paulo, v. 4, nº 1, p. 79-93.

, (2002a) A "progressão continuada" e a "democratização" do ensino. XI ENDIPE: Encontro Nacional de Didática e Prática de Ensino. Goiânia, maio. Manaus: Sonopress Rimo da Amazônia. CD-ROM. 
FRIGERIO, Graciela, (2002). As reformas educacionais reformam as escolas ou as escolas reformam as reformas? In: UNESCO. Oficina Regional de Educación de la UNESCO para América Latina y el Caribe. Educação na América Latina: análise de perspectivas. Brasília: UNESCO e OREALC, p. 193-214.

GARCIA, Clarice Aparecida Alencar, (2001). Ciclos e qualidade de ensino: uma relação complexa. $24^{\mathrm{a}}$ Reunião Anual da ANPEd, Caxambu, MG. Disponível em: <www.anped.org.br/ 24/P0561543907875.doc>.

GOMES, Candido Alberto, (1994). A educação em perspectiva sociológica. $3^{\text {a }}$ ed. São Paulo: EPU.

, (2002). Planos de papel e planos realizadores: a diferença do pacto educacional. In: GOMES, Candido Alberto (org.). Traduzindo em ações o Plano Nacional de Educação. Brasília: UNESCO e Comissão de Educação do Senado Federal, p. 199-208.

GUIMARÃES, Maria Nazaré do Nascimento, (2001). Práticas pedagógicas em época de progressão continuada: um olhar sobre a avaliação. Dissertação de mestrado. Faculdade de Educação da Universidade Federal de São Carlos.

LIMA, Ana Ignez Belém, (1995). A professora alfabetizadora: caminhos e descaminhos na construção de uma identidade. Dissertação de mestrado. Faculdade de Educação da Universidade Federal do Ceará.

MAINARDES, Jefferson, (1995). Ciclo básico de alfabetização : da intenção à realidade (avaliação do CBA no município de Ponta Grossa, PR). Dissertação de mestrado. Faculdade de Educação da Universidade Estadual de Campinas.

, (1998). A promoção automática em questão: argumentos, implicações e possibilidades. Revista Brasileira de Estudos Pedagógicos, v. 79, nº 192, p. 16-29.

, (2001). A organização da escolaridade em ciclos: ainda um desafio para os sistemas de ensino. In: FRANCO, Creso (org.). Avaliação, ciclos e promoção na educação. Porto Alegre: Artmed, p. 35-54.

MAMEDE, Inês Cristina de Melo, (2000). Professoras alfabetizadoras : quem são, o que pensam e como alfabetizam. Tese de doutorado. Faculdade de Educação da Universidade Federal do Ceará.

MARQUES, Waldemar, (1991). O ensino público estadual do $1^{\circ}$ grau na Grande São Paulo : o ciclo básico em questão. Dissertação de mestrado. Faculdade de Educação da Universidade Estadual de Campinas.
MICHELOTTO, Regina Maria, (1988). O trabalho pedagógico do professor em Matemática: uma análise do ciclo básico no Paraná. Dissertação de mestrado. Faculdade de Educação da Universidade Federal do Paraná.

MONTEIRO, Rosana Batista, (1996). Resgatando o passado: o ciclo básico e a reprodução da Reforma do Ensino Primário de 1967. Dissertação de mestrado. Faculdade de Educação da Universidade Estadual de Campinas.

NÉBIAS, Cleide Marly, (1990). O ciclo básico e a democratização do ensino: do discurso proclamado às representações. Tese de doutorado. Escola de Comunicação da Universidade de São Paulo.

NEGRI, Itelma Miriam Alves de Medeiros, (1994). Ciclo básico de alfabetização: os limites de um projeto político. Dissertação de mestrado. Faculdade de Educação da Universidade Metodista de Piracicaba.

PARO, Vitor Henrique, (2000). Por que os professores reprovam: resultados preliminares de uma pesquisa. Ensaio: Avaliação e Políticas Públicas, v. 8, nº 28, p. 273-282. , (2001). Reprovação escolar: renúncia à educação. São Paulo: Xamã.

RODRIGUEZ, Andréa Maria Rua, (2002). Avaliação do ensino por ciclos de formação: currículo, pedagogia e avaliação na perspectiva de professoras engajadas de uma escola municipal. Dissertação de mestrado. Faculdade de Educação da Universidade Federal do Rio Grande do Sul.

SILVA, Rose Neubauer da, DAVIS, Claudia, (1994). É proibido repetir. Brasília: MEC, Secretaria de Educação Fundamental e UNESCO.

SILVA, Rose Neubauer da, DAVIS, Claudia, ESPOSITO, Yara Lúcia, (1996). Um estudo sobre os professores que atuam nas séries iniciais. In: SERBINO, Raquel Volpato et al. Formação de professores. São Paulo: Universidade Estadual Paulista, p. 237-248.

SCHEERENS, Jaap, (2000). Improving school effectiveness. Paris: UNESCO-IIEP.

SCHEERENS, Jaap, BOSKER, Roel, (1997). The foundations of educational effectiveness. Oxford: Pergamon.

SILVA, Marcelo Soares Pereira da, MELLO, Flávia Carvalho Malta de, (2001). Políticas para enfrentamento do fracasso escolar : uma análise da proposta Escola Plural de Belo Horizonte. 24ㄹ Reunião Anual da ANPEd, Caxambu, MG. Disponível em: <www.anped.org.br/24/P0568099736774.doc>. 
SOARES, Cláudia Caldeira, (2002). Reinventando a escola: os ciclos de formação na Escola Plural. São Paulo: Annablume.

SOUSA, Clarilza Prado de, (1999). Limites e possibilidades dos programas de aceleração de aprendizagem. Cadernos de Pesquisa, $\mathrm{n}^{\circ} 108$, p. 81-99.

SOUSA, Sandra M. Zákia L., ALAVARSE, Ocimar Munhoz, (2002). Ciclos: a centralidade da avaliação. XI ENDIPE: Encontro Nacional de Didática e Prática de Ensino. Goiânia, maio. Manaus: Sonopress - Rimo da Amazônia. CD-ROM.

SOUZA, Eny da Glória Marques de, (2000). Classes de aceleração da aprendizagem em Campo Grande - MS. Em Aberto, Brasília, v. $17, \mathrm{n}^{\circ} 71$, jan., p. 149-151.

TEDESCO, Juan Carlos, (1998). O novo pacto educativo : educação, competitividade e cidadania na sociedade moderna. São Paulo: Ática.

TEIXEIRA, Anísio S., (1983). Valores proclamados e valores reais nas instituições escolares brasileiras. Revista Brasileira de Estudos Pedagógicos, v. 64, n 148, p. 243-256.

VASCONCELLOS, Celso dos S., (1999). Ciclos de formação: um horizonte libertador para a escola no $3^{\circ}$ milênio. Revista de Educação AEC, n 111, p. 83-95.

VIANNA, Heraldo Marelim, (1992). Desempenho dos alunos do ciclo básico de alfabetização em Minas Gerais: análise dos resultados e identificação de pontos críticos. Estudos em Avaliação Educacional, $\mathrm{n}^{\circ}$ 6, p. 43-62.

VIANNA, Heraldo, SQUÁRCIO, Nilza do Carmo, VILHENA, Maria das Graças Costa de, (1992). As escolas estaduais de Minas Gerais e o CBA. Estudos em Avaliação Educacional, $\mathrm{n}^{\circ} 6$, p. 63-84.

WALLER, Willard, (1967). The sociology of teaching. New York: Wiley \& Sons.

ZAPPONI, Neuza., (1991). Experiências de implantação do ciclo básico: tentativas de diminuição das deficiências na alfabetização. In: CADEMARTORI, Lígia (org.). O desafio da escola básica : qualidade e eqüidade. Brasília; IPEA, p. 119-126.

Recebido em novembro de 2003 Aprovado em dezembro de 2003 